\title{
Efeito do Óleo de Piper aduncum no Controle em Pós-Colheita de Colletotricum musae em Banana
}

\author{
Cleber N. Bastos \& Paulo Sérgio B. Albuquerque \\ CEPLAC/SUPOR/ERJOH, Cx. Postal 46, 67105970, Marituba, PA, e-mail: cleber@ufpa.br
}

(Aceito para publicação em 11/05/2004)

Autor para correspondência: Cleber N. Bastos

BASTOS, C.N. \& ALBUQUERQUE, P.S.B. Efeito do óleo de Piper aduncum no controle em pós-colheita de Colletotrichum musae em banana. Fitopatologia Brasileira 29:555-557. 2004.

\section{RESUMO}

Em pós-colheita, a podridão dos frutos causada por Colletotrichum musae é a doença mais importante da banana (Musa spp.). Testes in vitro e in vivo foram realizados com o objetivo de avaliar o efeito fungitóxico do óleo essencial de pimenta-de-macaco (Piper aduncum) sobre o patógeno. Nas concentrações acima de $100 \mu \mathrm{g} / \mathrm{ml}$, o óleo inibiu, em 100\%, o crescimento micelial e a germinação dos conídios. No teste in vivo foram usados frutos de banana "Prata", nos quais foram feitos orifícios com vasador de rolhas $(0,5 \mathrm{~cm}$ de diâmetro) e colocados $20 \mu$ l de suspensão de conídios ( 2 x 104 conídios $/ \mathrm{ml}$ ) e, em seguida, aplicados $20 \mu \mathrm{l}$ de diferentes concentrações do óleo. Os resultados mostraram que o óleo na concentração 1\% foi eficaz, sendo capaz de impedir a manifestação de podridões nos frutos de banana.

Palavras-chave adicionais: antracnose, Musa spp., fruto, podridão.

\section{ABSTRACT}

The effect of essential oil of Piper aduncum in controlling Colletotrichum musae on post harvest bananas

Banana (Musa spp.) fruit rot caused by Colletotrichum musae is the most serious post harvest disease. In vitro and in vivo tests were carried out to evaluate the fungitoxicity of the essential oil of Piper aduncum (pimenta-de-macaco) against the pathogen. The oil at concentrations above $100 \mu \mathrm{g} / \mathrm{ml}$ completely inhibited the mycelial growth and spore germination. In vivo testing was performed by making holes in the bananas and filling the holes with $20 \mu \mathrm{l}$ of spore suspension and $20 \mu \mathrm{l}$ of oil dilution. The results showed that at a dilution of $1 \%$ the development of banana rot was avoided.
As doenças de pós-colheita em frutos de banana (Musa spp.) são de grande importância, principalmente para as frutas destinadas à exportação, destacando-se a antracnose causada por Colletotrichum musae (Berk. \& Curtis) Arx.

Para o controle da doença vêm sendo utilizados tratamento químico e práticas culturais, visando reduzir a quantidade de inóculo no campo. Em pós-colheita, as medidas de controle são constituídas principalmente de fungicidas. A restrição ao uso de fungicidas, devido à fitotoxicidade, efeitos residuais, espectro de ação e resistência pelo patógeno, tem levado a procura de métodos alternativos de controle tais como, uso de biofungicidas, extratos vegetais e óleos essenciais. Os resultados alcançados nessa linha de pesquisa têm-se mostrado promissores para uma utilização prática no controle de fitopatógenos em diversas culturas (Franco \& Bettiol, 2000; Benato et al., 2002; Carré et al., 2002; Moreira et al., 2002).

Alves et al. (2002) e Alves et al. (2003) relataram a eficiência dos monoterpenos citral, citronelal e dos óleos essenciais das plantas Cymbopogon citatrus (D.C.) Stapf., C. nardus Rendl. e Eucalyptus citriodora Hooker no controle in vitro, da germinação de conídios e do crescimento micelial de C. musae.

As espécies do gênero Piper (Piperaceae) são amplamente aplicadas na medicina popular em função das propriedades microbianas exibidas por seus constituintes. pimenta-de-macaco (Piper aduncum L.) é excelente produtora de óleo essencial, o qual possui alto teor do éter fenílico dilapiol (Maia et al., 1998). Produtos naturais de P. aduncum têm apresentado ação eficaz no controle de fitopatógenos (Nair \& Burke, 1990). Bastos (1997) demonstrou, in vitro e in vivo, a ação inibitória do óleo essencial de P.aduncum contra Crinipellis perniciosa (Stahel) Singer, agente causal da vassoura-de bruxa do cacaueiro (Theobroma cacao L.) e a inibição in vitro do crescimento micelial de vários fitopatógenos.

O presente trabalho teve como objetivo verificar, in vitro e in vivo, o efeito fungitóxico do óleo de $P$. aduncum sobre C. musae, como forma alternativa de controle da antracnose em frutos de banana em pós-colheita.

\section{Teste in vitro}

O óleo essencial foi extraído a partir de folhas secas de $P$. aduncum pelo método de hidrodestilação como descrito por Maia et al. (2001). O isolado de C. musae foi obtido a partir de frutos de banana oriundos de supermercados da Região Metropolitana de Belém, PA. Foram realizados dois ensaios in vitro para verificação do efeito do óleo essencial de P. aduncum, em várias diluições, sobre o crescimento micelial e a germinação de conídios do patógeno. Para o teste de crescimento, alíquotas do óleo foram adicionadas ao meio de cultura BDA, fundente, 
e vertido em placas de Petri para as concentrações finais de 10, 50, 100 e $150 \mu \mathrm{g} / \mathrm{ml}$. Discos de 0,5 cm de diâmetro foram retirados de colônias do fungo e colocados no centro das placas que foram incubadas em câmara de crescimento com fotoperíodo de 12 h e temperatura de $25^{\circ} \mathrm{C}$. Após oito dias de incubação, foi medido o diâmetro da colônia, sendo, posteriormente, quantificada a percentagem de inibição do crescimento micelial em relação à testemunha.

Para o teste de germinação foi preparada uma suspensão de conídios numa solução nutritiva (Tuite, 1969) na concentração de $2 \times 10^{4}$ conídios/ml. Alíquotas de $100 \mu \mathrm{l}$ desta suspensão foram pipetadas em lâminas escavadas contendo óleo de $P$. aduncum para diferentes concentrações finais de 10, 50, 100 e $150 \mu \mathrm{g} / \mathrm{ml}$. As lâminas foram incubadas por $48 \mathrm{~h} \mathrm{em}$ câmara úmida, sendo, a seguir, avaliadas as germinações em microscópio óptico. Foram considerados como esporos germinados aqueles que apresentaram tubo germinativo, independente do seu comprimento. O delineamento experimental foi inteiramente casualizado com quatro repetições.

\section{Teste in vivo}

Os frutos de banana "Prata" utilizados no ensaio foram colhidos no estádio de maturação, com a casca ainda verde, na Estação de Recursos Genéticos de Cacau José Haroldo (ERJOH) e lavados em solução de hipoclorito de sódio 0,5\% (v/v) e duas vezes em água de torneira. Após secagem em bandejas de plástico, foi efetuado um orifício com vasador de rolha $(0,5 \mathrm{~cm}$ de diâmetro) a uma profundidade de aproximadamente $2 \mathrm{~mm}$ na parte mediana dos frutos. Em cada orifício foram colocados $20 \mu \mathrm{l}$ de uma suspensão de conídios de $C$. musae ( $2 \times 10^{4}$ conídios $/ \mathrm{ml}$ ) e, em seguida, foram aplicados $20 \mu \mathrm{l}$ do óleo nas concentrações de $0,05 \%, 0,1 \%, 0,3 \%, 0,5 \%$ e $1,0 \%$. Como testemunha, foram empregados frutos com e sem inoculações do patógeno. Como tratamento padrão foram utilizados frutos tratados à mesma maneira, com o fungicida benomil a $0,1 \%$. Para cada tratamento foram empregados dez frutos, sendo cada fruto constituído de uma repetição. Após as inoculações, os frutos foram incubados em caixas de papelão à temperatura de $25^{\circ} \mathrm{C}$ e UR em torno de $80-85 \%$. As avaliações foram efetuadas aos oito dias após as inoculações, mediante a determinação da incidência (número de frutos infetados em cada tratamento) e da severidade da doença (superfície externa do fruto ocupada por lesão em \%).

De acordo com os resultados referentes ao efeito do óleo essencial na inibição do crescimento micelial e na germinação de conídios de C. musae (Tabela 1), observa-se que houve $100 \%$ de inibição na germinação e no crescimento, nas concentrações de $100 \mu \mathrm{g} / \mathrm{ml}$ e $150 \mu \mathrm{g} / \mathrm{ml}$, respectivamente. Quanto ao efeito do óleo no controle da podridão de frutos, verificou-se que todos os tratamentos reduziram a incidência e a severidade da doença, em comparação com a testemunha (Tabela 2). O melhor desempenho para o controle da doença foi obtido com o óleo a 1,0\%, com controle semelhante ao fungicida benomil.

Pelo exposto, evidencia-se que o óleo essencial de $P$. aduncum pode vir a ser usado como alternativa ao controle da antracnose, integrando as técnicas de pós-colheita com as técnicas de pré-colheita. Essas técnicas que consistem no emprego de extratos vegetais, aminoácidos, microrganismos e, agora óleos essenciais, enquadram em estratégias de controle biológico de patógenos de plantas (Franco \& Bettiol, 2000). Com os resultados obtidos neste trabalho, pode-se concluir que o óleo de $P$. aduncum, além de ser um produto biológico natural, apresenta potencial de uso para o controle da podridão de frutos de banana causada por C. musae em pós-colheita, com a vantagem de minimizar o uso dos fungicidas convencionais, de preservar o meio ambiente e proteção a saúde do consumidor. Neste contexto, o óleo deve ser testado em condições comerciais visando o controle da antracnose em pós-colheita em frutos de banana.

TABELA 1 - Efeito do óleo essencial de Piper adunum sobre Colletotrichum musae, in vitro (\% de inibição do crescimento micelial e da germinação de conídios) ${ }^{1}$

\begin{tabular}{ccc}
\hline \hline $\begin{array}{c}\text { Concentração } \\
\text { do óleo }(\boldsymbol{\mu} \mathbf{g} / \mathbf{m l})\end{array}$ & $\begin{array}{c}\text { Inibição do } \\
\text { crescimento micelial }(\%)\end{array}$ & $\begin{array}{c}\text { Inibição da } \\
\text { germinação (\%) }\end{array}$ \\
\hline 10 & $3,4^{2} \mathrm{c}$ & $1,1^{2} \mathrm{~b}$ \\
50 & $79,4 \mathrm{~b}$ & $83,4 \mathrm{a}$ \\
100 & $85,4 \mathrm{ab}$ & $100,0 \mathrm{a}$ \\
150 & $100,0 \mathrm{a}$ & $100,0 \mathrm{a}$ \\
\hline
\end{tabular}

${ }^{1}$ Em relação à testemunha $(0 \mathrm{ppm})$; média de quatro repetições.

${ }^{2}$ Médias seguidas por letras distintas na vertical diferem entre si pelo teste de Tukey ( $\mathrm{P}=0,05 \%)$.

TABELA 2 - Controle da podridão causada por Colletotrichum musae em frutos de banana (Musa spp.) 'Prata' com óleo essencial de Piper aduncum $(\mathrm{PA})^{1}$

\begin{tabular}{|c|c|c|}
\hline Tratamento & Incidência (I) ${ }^{2}$ & Severidade $(\mathrm{S})^{3}$ \\
\hline Testemunha & 100,0 & 34,9 \\
\hline Óleo PA $0,05 \%$ & 90,0 & 33,7 \\
\hline Óleo PA $0,1 \%$ & 30,0 & $5,1^{*}$ \\
\hline Óleo PA 0,3\% & 20,0 & $4,9^{*}$ \\
\hline Óleo PA 0,5\% & 10,0 & $1,8^{*}$ \\
\hline Óleo PA 1,0\% & 0,0 & $0,0^{*}$ \\
\hline Benomil 0,1\% & 0,0 & $0,0^{*}$ \\
\hline
\end{tabular}

${ }^{1}$ Leitura após oito dias de incubação a $25{ }^{\circ} \mathrm{C}$ e $80-85 \%$ UR. Dez frutos por tratamento;

${ }^{2} \mathrm{I}=\left(\mathrm{N}^{\circ}\right.$ de frutos infetados $/ \mathrm{N}^{\circ}$ total de frutos $) \times 100$;

${ }^{3} \mathrm{~S}=$ (Diâmetro médio da lesão / tamanho do fruto) x 100;

*Tratamentos diferem significativamente da testemunha com inóculo (Teste $\mathrm{t}, \mathrm{P}<0,01)$

\section{REFERÊNCIAS BIBLIOGRÁFICAS}

ALVES, E.S.S., SANTOS, M.P., VENTURA, J.A. \& FERNANDES, P.M.B. Eficiência de óleos essenciais no controle in vitro da germinação de conídios e do crescimento micelial de Colletotrichum musae. Fitopatologia Brasileira 27:75. 2002 (Resumo).

ALVES, E.S.S., PUPO, M.S., MARQUES, S.S., ILCHES, T.T.B., SANTOS, R.B., VEENTURA, J.A. \& FERNANDES, M.P.M. 
Efeito do óleo de Piper aduncum no controle em pós-colheita de...

Avaliação de óleos essenciais na inibição do crescimento de fungos de fruteiras. Fitopatologia Brasileira 28:343. 2003 (Resumo).

BASTOS, C.N. Efeito do óleo de Piper aduncum sobre Crinipellis perniciosa e outros fungos fitopatogênicos. Fitopatologia Brasileira 22:441-443. 1997.

BENATO, E.A., SIGRIS, J.M.M., HANASHIRO, M.M., MAGALHÃES, M.J.M. \& BINOTTI, C.S. Avaliação de fungicidas e produtos alternativos no controle de podridões pós-colheita em maracujá-amarelo. Summa Phytopathologica 28:299-304. 2002.

CARRÉ, V., ZANELLA, A.L., BECKER, A., STANGARLIN, J., PAGLIOSA, L.A., SCHWAN-ESTRADA, K.R.F. \& GONÇALVES

JR, A.C. Fungitoxicidade de quitosana e extrato de Artemisia camphorata a Colletotrichum musae. Fitopatologia Brasileira 27:291. 2002 (Resumo).

FRANCO, D.A. \& BETTIOL, W. Controle de Penicillium digitatum em pós-colheitade citros com produtos alternativos. Fitopatologia Brasileira 25:602-606. 2000.
MAIA, J.G.S., ZOGHBI, M.G.S., ANDRADE, E.H.A., SANTOS, A.S., SILVA, M..L., LUZ, A.I.R. \& BASTOS, C.N. Constituents of the essential oil of Piper aduncum L. growing in the Amazon Region. Flavour and Fragrance Journal 13:269-272. 1998.

MAIA, J.G.S., ZOGHBI, M.G.B. \& ANDRADE, E.H.A. Plantas aromáticas na Amazônia e seus óleos essenciais. Belém: Museu Paraense Emílio Goeldi. 2001.

MOREIRA, L.M., MAY-DE MIO, L.L., ALDEBENITOSANHUEZA, R.M., LIMA, M.L.R.Z. \& POSSAMAI, J.C. Controle em pós-colheita de Monilia Fructicola em pêssegos. Fitopatologia Brasileira 27:395-398. 2002.

NAIR, M.G. \& BURKE, B.A. Antimicrobial Piper metabolite and related compounds. Journal of Agriculture and Food Chemistry 38:1093-1906. 1990.

TUITE, J. Plant Pathological methods fungi and bacteria. Minneaples Burgess. 1969. 